\title{
Performance Management of Small and Medium-sized Enterprises in Morocco
}

\author{
Benazzi Khadija \\ Teacher - researcher \\ Faculty of Legal, Economic and Social Sciences \\ Research Group in Innovation, Responsibilities and Sustainable Development
}

(INREED)

Cadi Ayyad University, Morocco

E-mail: khadija.benazzi@gmail.com

Razzouki Mustapha (Corresponding author)

PhD students in management sciences

Faculty of Legal, Economic and Social Sciences

Research Group in Innovation, Responsibility and Sustainable Development (INREED)

University Cadi Ayyad, Morocco

E-mail: razzouki.mustapha@gmail.com

Received: May 24, 2020 Accepted: June 15, 2020 Published: July 1, 2020

doi:10.5296/bms.v11i1.17284 URL: https://doi.org/10.5296/bms.v11i1.17284

\begin{abstract}
Sustainable economic growth depends on many factors, the most important of which is the growth of small and medium-sized enterprises. As an independent and indispensable element of a market economy, small and medium-sized enterprises contribute to the structural restructuring of the economy, strengthen regional economic base, increase overall production, creates a favorable environment for the development of competition, creates jobs for a large part of the population and stimulates scientific and technological progress. Despite understanding the value of the human element in achieving success at the organizational level,


relatively few SMEs managers pay attention to implementing and using the performance management system. The goal of this paper is to assess the level of performance management tools and techniques used by Moroccan small and medium-sized enterprises in their activities.

Keywords: performance management, small and medium-sized enterprises

\section{Introduction}

Small and medium-sized enterprises (SMEs) are playing an increasingly important role in raising GDP, goods production; meeting people's needs; economic development; generating employment; and transforming the economic structure in most countries of the world.

In Africa, SMEs represent the majority of enterprises and play a great role in the development of the economy. They represent $90 \%$ of the private sector and $50 \%$ of employment in most African countries (UNIDO, 1999). This category of companies provides the best structure for developing new methods and techniques of management. Consequently, the activities of SMEs enrich management tools and increase organizational efficiency by effectively resolving the various problems they face in their economic development at different times.

In Morocco, the number of small and medium-sized enterprises has increased considerably since the 1990s, both in terms of statistics and in terms of the diversity of their activities. They account for 29 percent of all Moroccan companies, 95 percent of the national productive fabric, 40 percent of private investment and 30 percent of exports (Bentaleb \& Louitri, 2011). Given these indicators, the Moroccan State has placed SMEs at the center of its development policy, aware that they must increase their size (increase the number of employees, diversify their markets, etc.) in order to have a significant impact on the economy.

In this context, the value of individual employee performance can not be ignored and can have an impact on the long-term success of an organization. The performance of employees is their ability to perform their assigned tasks successfully.

Finally, the performance of the company involves a mutual agreement between managers and staff on the objectives to be achieved. This is not an easy task given the many different jobs and the frequent changes in employees' roles and responsibilities. Management needs to have a process for this; we would say a performance management system.

\section{Definitions and Concepts of Performance Management}

Many definitions of performance management have been suggested. In the traditional approach, performance management was assimilated to performance measurement, which consisted primarily of assessing whether each employee carried out the assigned tasks.

Ferreira and Otley (2009) defined the performance management system as: "the evolving formal and informal mechanisms, processes, systems, and networks used by organizations for conveying the key objectives and goals elicited by management, for assisting the strategic 
process and ongoing management through analysis, planning, measurement, control, rewarding, and broadly managing performance, and for supporting and facilitating organizational learning and change". This definition indicates a holistic PMS approach.

Management performance is a broad term that has come to stand for the set of practices through which work is defined and reviewed, capabilities are developed, and rewards are distributed within organizations. It may include setting goals, selecting and placing workers, evaluating performance, compensating, training and development, and managing careers.

Armstrong and Baron (1998) defined performance management as: "a process which contributes to the effective management of individuals and teams in order to achieve high levels of organizational performance. As such, it establishes shared understanding about what is to be achieved and an approach to leading and developing people which will ensure that it is achieved".

Performance management is based on the principle that improving individual performance will improve organizational performance. On the basis of this principle, human resource management practices will not lead to a certain level of organizational performance, but will make a significant contribution to making employees competent, dedicated and motivated who are likely to work harder than necessary to carry out their tasks.

The Department of Human Resources frequently designs and maintains the performance management system. Over time, performance management has become the most important tool for managers to ensure a proper interpretation of all aspects of human resources activities. This allows line managers to ensure that their employees know what to do, have the skills to do so, and carry out their duties in compliance with expectations (Mohrman \& Mohrman, 1995).

Michael Armstrong, in their manual (2006) Performance Management: Key Strategies and Practical Guidelines, defined performance management as a systematic process for improving organizational performance by developing the performance of individuals and teams. This process becomes a company's main management tool by significantly influencing individual behavior by directing it towards the achievement of the organization's strategic objectives.

In other words, performance management must be:

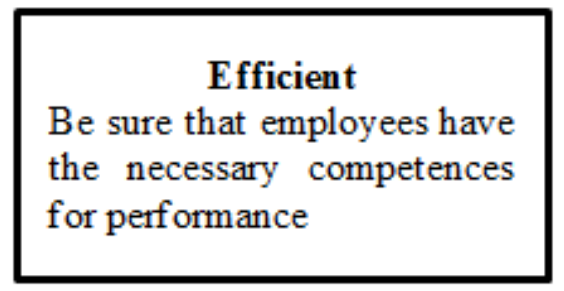

\begin{tabular}{|c|c|}
\hline $\begin{array}{l}\text { Strategic } \\
\text { It's about broader } \\
\text { problems and long-term } \\
\text { goals. }\end{array}$ & $\begin{array}{l}\text { Integrated } \\
\text { Various aspects of business, } \\
\text { people management and } \\
\text { individuals and teams should be } \\
\text { linked together. }\end{array}$ \\
\hline
\end{tabular}

Performance management is an instrument for ensuring that line managers effectively manage the people they are responsible for and in line with organizational goals and objectives.. It is the primary means by which they ensure that: 
- Employees know and understand what they want from them.

- Employees have the abilities and skills to meet these expectations.

- Employees receive feedback on their performance.

The procedure should therefore be simple and descriptive and easily understood by those concerned. Managers and individuals should consider what performance improvement they are trying to do, and not just how to do it.

Finally, everyone will be able to understand how the findings will be applied and what the implications will be for themselves and their organization.

\section{Performance Management in Moroccan SMEs: an Empirical Study}

Such a study has been difficult to carry out in order to achieve our objective because, according to the authors' knowledge, there is no previous research on performance management within Moroccan SMEs. Thus, we established a questionnaire to define the key aspects of performance management in this type of company, based on a previous study conducted by the Chartered Institute of Personnel and Development from London in 2009, even though these studies covered a wide range of enterprises, particularly large ones.

The principal questions concerned the understanding of the concept, the establishment of performance standards for employee evaluation. the expected results of its implementation, the main beneficiaries of the system, the results of its implementation, the other human resources processes that must be linked to performance management, and the means of assessing its effectiveness.

\subsection{Data Collection and Sample}

The data were collected by questionnaire sent to the company managers. The fieldwork was carried out in January and February 2020. The target population is composed of companies with between 10 and 250 employees. The initial sample was based on five relevant performance management issues: the existence of a human resources department, a human resources planning system and a job description for all workplaces in the organization, training plans and a performance assessment system. Then, we selected companies that responded positively to at least three of these questions. The sample thus obtained consists of 87 SMEs, including 10 small enterprises, with a total of 7165 employees.

\subsection{Main Results of the Survey}

The first question concerns the cornerstones of performance management.

Fifty-eight of the respondents indicated that performance evaluation is the main activity that should be part of such a system, Monitor the progress of the employee (forty-nine), target-setting (forty-two), rewards that will be distributed (40) and regular feedback (Fifty-three). Figure 1 illustrates the cornerstones of performance management. 


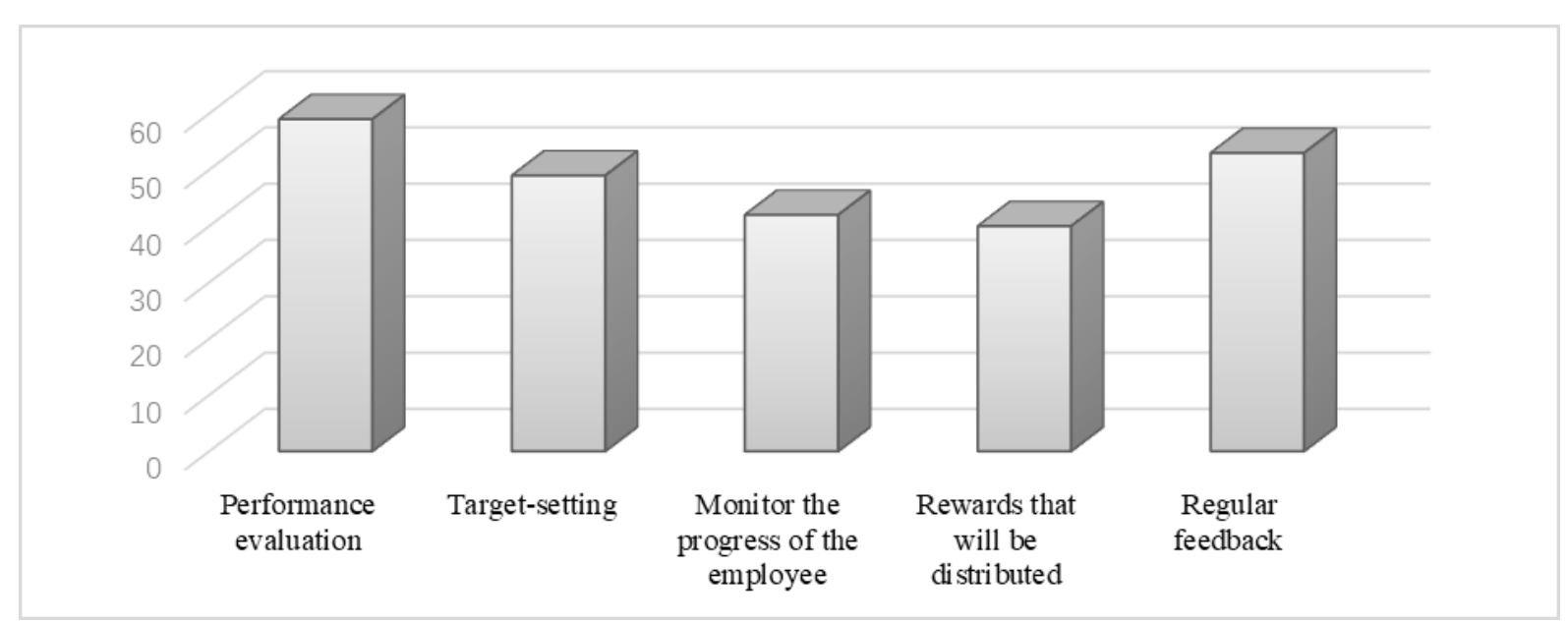

Figure 1. The cornerstones of performance management

The second question concerns the establishment of performance standards for the assessment of employees.

Over three-quarters of interviewees indicated that the Branch sets standards often in collaboration with other entities. For the entities consulted, the majority of respondents $(60 \%)$ indicated that the branch collaborates with the human resources department, supervisors $(21 \%)$ or employee representatives $(19 \%)$.

Subsequently, the persons in the sample analyzed were invited to provide their opinion on the expected results of the implementation of the performance management system. The responses are summarized in Table 1.

As can be seen, there are significant differences in the response. The effect on individuals and the company as a whole seems to have had the most answers. Almost $50 \%$ agreed that the use of such a system would have a positive impact on individual performance, while $62 \%$ felt that the system would help employees to better understand their tasks and how to do them.

In addition, almost 47 of the interviewees believe that a Performance Management System will have a positive impact on the performance of the organization. At the same time, almost a third of them do not agree or disagree with this proposal. 
Table 1. Expected results of the implementation of a performance management system.

\begin{tabular}{|c|c|c|c|c|c|}
\hline & $\begin{array}{c}\text { Strongly } \\
\text { agree }\end{array}$ & Agree & $\begin{array}{c}\text { Nor agree or } \\
\text { disagree }\end{array}$ & Disagree & $\begin{array}{l}\text { Strongly } \\
\text { disagree }\end{array}$ \\
\hline $\begin{array}{l}\text { Performance management has a positive impact on } \\
\text { individual performance. }\end{array}$ & $8 \%$ & $53 \%$ & $31 \%$ & $6 \%$ & $2 \%$ \\
\hline $\begin{array}{l}\text { Performance management has a positive impact on } \\
\text { organizational performance. }\end{array}$ & $5 \%$ & $54 \%$ & $29 \%$ & $10 \%$ & $2 \%$ \\
\hline $\begin{array}{l}\text { Performance management helps employees better } \\
\text { understand their work. }\end{array}$ & $11 \%$ & $62 \%$ & $20 \%$ & $6 \%$ & $1 \%$ \\
\hline $\begin{array}{l}\text { Performance management helps line managers } \\
\text { better manage their employees. }\end{array}$ & $9 \%$ & $42 \%$ & $30 \%$ & $15 \%$ & $4 \%$ \\
\hline $\begin{array}{l}\text { Performance management helps individuals } \\
\text { develop their skills and career choices. }\end{array}$ & $6 \%$ & $32 \%$ & $48 \%$ & $12 \%$ & $2 \%$ \\
\hline $\begin{array}{l}\text { Performance management can have an impact on } \\
\text { the well-being of employees. }\end{array}$ & $18 \%$ & $43 \%$ & $28 \%$ & $8 \%$ & $7 \%$ \\
\hline $\begin{array}{l}\text { Performance management helps staff understand } \\
\text { the organization's strategic priorities. }\end{array}$ & $24 \%$ & $56 \%$ & $12 \%$ & $5 \%$ & $3 \%$ \\
\hline $\begin{array}{l}\text { Performance management helps employees } \\
\text { understand how their behaviours affect the } \\
\text { achievement of the organization's strategic } \\
\text { priorities. }\end{array}$ & $21 \%$ & $53 \%$ & $19 \%$ & $4 \%$ & $3 \%$ \\
\hline
\end{tabular}

It can be seen that there is a significant difference. More than one third considered a performance management system to help line managers to manage their employees, while only thirty-two percent agreed that such a system could help employees develop their skills and career choices.

A similar situation can be identified with regard to the impact on the well-being of employees. Only one third of the interviewees acknowledged that performance management is helping employees to improve their well-being. The number of undecided persons is almost one-third, while eight percent disagree.

With respect to the relationship between employees and organizational objectives, more than half of respondents agreed that performance management would help employees understand 
the organization's strategic priorities and Three per cent recognized that such a system would help employees understand how their actions would affect their performance.

As can be seen in Figure 2, 45\% indicated the employee, which is consistent with the answer given in the previous question, where $48 \%$ considered that such a system would have a positive impact on the employee's performance (see Table 1).Second, the line manager leads with $20 \%$, while more than $40 \%$ believe that implementing a performance management system enables line managers to better manage their employees.

At the same time, those who consider the organization to be the main beneficiary represent less than twenty percent even though, in the previous question, almost 60 percent agreed that the implementation of a performance management system would improve the performance of the organization.

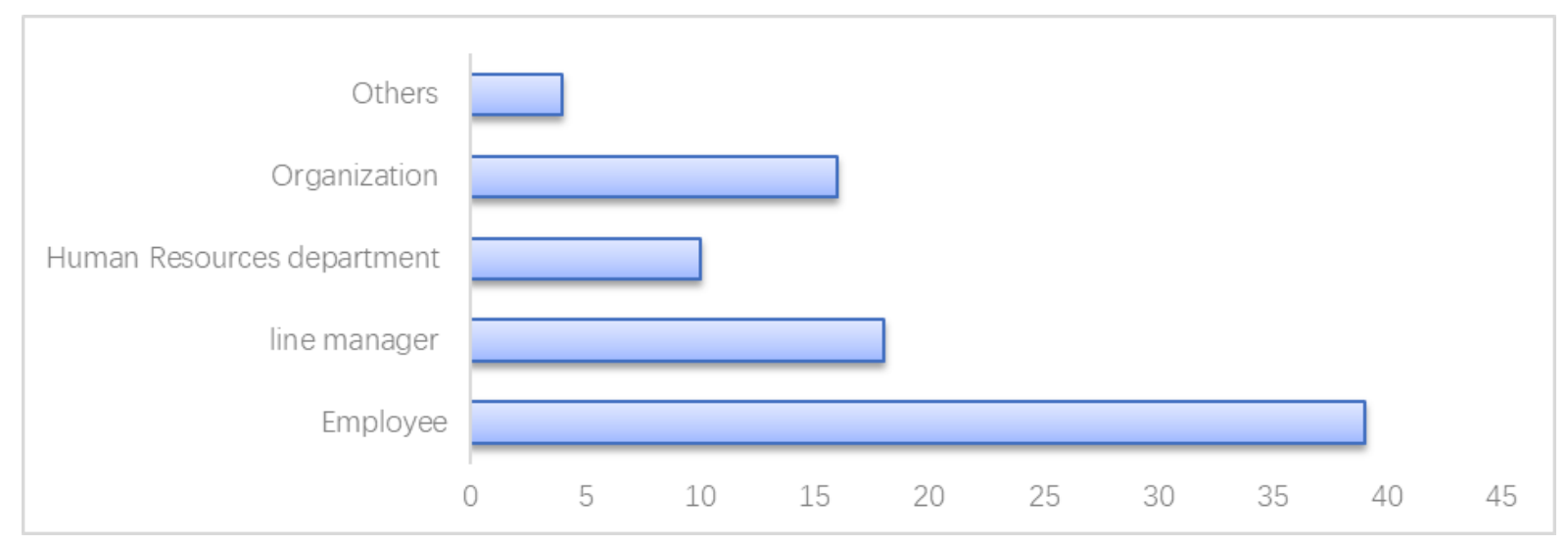

Figure 2. Main beneficiaries of the performance management system (in number)

The analysis based on the size of the company is most important. While about sixty-five percent of small businesses consider the employee to be the main beneficiary, and forty-four percent of medium-sized enterprises indicate the organization. This may be due to the fact that respondents could only choose one option.

The next question concerns other human resources processes which should be linked to performance management.

As can be seen in Figure 3, twenty-four respondents (nearly twenty-eight percent) reported training activities in general, followed by coaching (twenty percent), career development (seventeen percent) and work design activities (sixteen percent), while only sixty-two percent agreed that such a system would help employees better understand their work (see Table 1). 


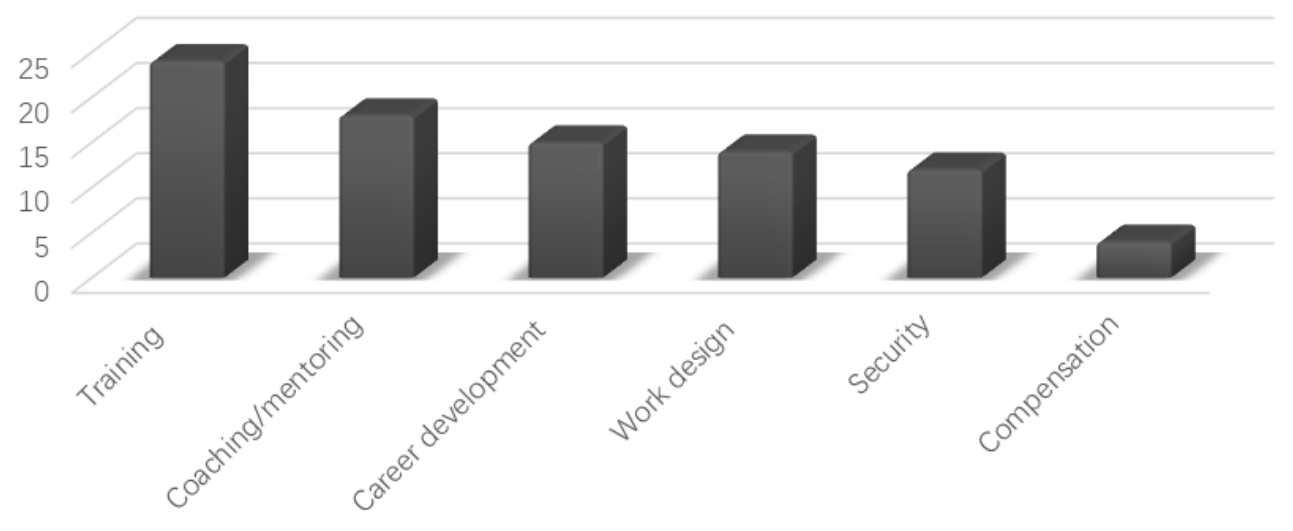

Figure 3. Other human resource processes related to performance management

Respondents were then asked how performance management should be evaluated. It is not surprising that the majority indicate individual organizational performance, $91 \%$ and $78 \%$ respectively. However, a wide range of measures is also suggested, with job satisfaction recommended as a measure of $(47 \%)$ followed by motivation $(39 \%)$.

Finally, respondents were asked how much influence the implementation of such a system has on the overall performance of the organization. As can be seen in Figure 4, sixty-seven per cent of respondents consider that such a system will have a significant or very important influence, whereas only seven per cent indicate that such a system has little influence on the performance of the organization.

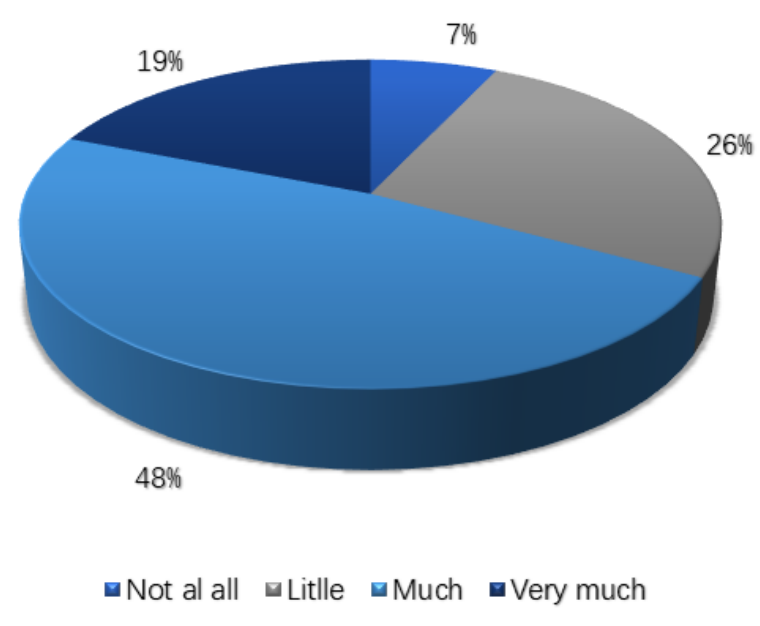

Figure 4. The influence of performance management implementation on overall performance

\section{Conclusions}

In general, the results of our study confirm that performance management is an important management tool and that its role is primarily to better manage employees. It is understood 
that its goal is to align individual interests and goals with those of the company while concentrating on strategic priorities. Such a system can also be seen as a powerful communication tool, particularly between line managers and their employees.

The study pointed out that performance management focuses on target-setting and performance evaluation, etc. We also note that this system is more often linked to other human resource management systems, such as training, coaching and career development.

The results of the survey showed that the majority of the companies surveyed had a complete picture of what performance means by linking it not only to their assessment, but also to the motivational systems. When performance management is linked to reward management, managers pay attention to how employees can achieve results and their impact on the rest of the team.

In conclusion, performance management is a complex and powerful tool that cannot be separated from other management systems. In high-performing companies, the implementation of such a system allows line managers to effectively carry out their responsibilities and obtain the best results.

\section{References}

Armstrong, M., Baron, A. (2009). Performance management: the new realities. London: Chartered Institute of Personnel and Development, 1998, in: Performance Management in Action. Current trends and practices [pdf].

Bentaleb, C., \& Louitri, A. (2011). La construction de la croissance des PME au Maroc. Management \& Avenir, p. 77 à 81.

Chartered Institute of Personnel and Development. (2009). Performance management in action, Current trends and practice, London: Chartered Institute of Personnel and Development, [pdf].

Ferreira, A., \& Otley, D. (2009). The design and use of performance management systems: an extended framework for analysis, Manag. Account. Res. 20 (2009) 263e282 https://doi.org/10.1016/j.mar.2009.07.003

Mohrman, A. M. Jr., \& Mohrman, S. A. (1995). Performance management is 'running the business'. Compensation \& Benefits Review. July-August. pp. 69-76. [pdf] https://doi.org/10.1177/088636879502700411

UNIDO. (1999). SMEs in Africa survive against all odds. http://www.unido.org/doc/ view? Document id=3927\&language_code=en, Accessed date: 9 November 2016. 


\section{Macrothink}

\section{Copyright}

Copyright for this article is retained by the author(s), with first publication rights granted to the journal.

This is an open-access article distributed under the terms and conditions of the Creative Commons Attribution license (http://creativecommons.org/licenses/by/4.0/). 